\title{
The comparison of spatial resolution of ion chamber, diode, and EBT3 film based on the dose profile
}

\author{
Han-Ping Hsueh ${ }^{1,2}$, Shyh-An Yeh ${ }^{1,2}$, Liyun Chang ${ }^{2}$ \\ ${ }^{1}$ Department of Radiation Oncology, E-Da Hospital, Kaohsiung, Taiwan; ${ }^{2}$ Department of Medical Imaging and Radiological Sciences, I-Shou \\ University Kaohsiung, Taiwan \\ Contributions: (I) Conception and design: L Chang; (II) Administrative support: SA Yeh; (III) Provision of study material or patients: None; (IV) \\ Collection and assembly of data: HP Hsueh; (V) Data analysis and interpretation: L Chang, HP Hsueh; (VI) Manuscript writing: All authors; (VII) \\ Final approval of manuscript: All authors. \\ Correspondence to: Shyh-An Yeh. Department of Radiation Oncology, E-Da Hospital, No. 1 Yida Road, Kaohsiung 82445, Taiwan. \\ Email: sayeh@outlook.com.
}

Background: It is essential for the physicist to quantify the dose of the radiation prior and during cancer treatment to ensure proper execution of the treatment plan. The most common way to measure the dose is utilizing Farmer chamber. The limitation of Farmer chamber is that it only provides dose of a specific point, while the beam dose profile is needed for the planning system. The Gafchromic EBT3 film can provide a quantitative dose profile in a 2D space. The EBT3 film has low energy dependence, similar effective atomic number to water, and self-developing; making it an ideal candidate for dose profile measurement.

Methods: Dose profiles of EBT3 was measured, analyzed and compared to semiflex chamber and EDGE detector under same conditions. The EBT3 films were placed at the center of RW3 water phantom $(30 \times 30 \times$ $30 \mathrm{~cm}^{3}$ ) under flattening filter free (FFF) Mode of Linac. The EBT3 films were calibrated by additional RW3 with a Farmer chamber under the stacked RW3 water phantom. Percentage depth dose (PDD) and Matlab were used to fit the dose curve of EBT3 and the results are presented.

Results: The penumbra of the measured dose profile through EBT3 film demonstrated little differences when comparing with that of the EDGE detector and noticeable differences when compared to that of the semiflex chamber. For a field size of $2 \times 2 \mathrm{~cm}^{2},(b=0.08$, depth of $5 \mathrm{~cm}$, beam off central axis $0.8 \mathrm{~cm})$, the measured difference of dose profile between EBT3 and EDGE detector is $-2.24 \%$. Under the same conditions, the dose profile difference between EBT3 and semiflex chamber is $10.59 \%$.

Conclusions: This study shows that EDGE detector has the highest spatial resolution to the dose profile. EBT3 film in combination with solid phantom can quickly sample dose profile in 2D. EBT3 film can be considered to be an excellent quality assurance (QA) tool with accurate dosimetry, a good spatial resolution and tolerable dose uncertainty.

Keywords: EBT3; EDGE detector; dose profile

Received: 28 March 2019; Accepted: 29 August 2019; Published: 30 September 2019.

doi: $10.21037 /$ tro.2019.09.02

View this article at: http://dx.doi.org/10.21037/tro.2019.09.02

\section{Introduction}

In response to a single high-dose treatment, the linear accelerator can utilize a flattening filter free (FFF) mode to increase the dose rate and shorten the treatment time. In FFF mode, the dose profile is not a flat curve. The accuracy of the dose calculation in the treatment planning system is affected by the actual dose distribution. Thus, it is crucial to determine the dose profile accurately.

The tools usually used to measure the dose profile are an ion chamber (1-5) or a diode dosimeter with higher spatial resolution (6-8). The above two tools require a water 


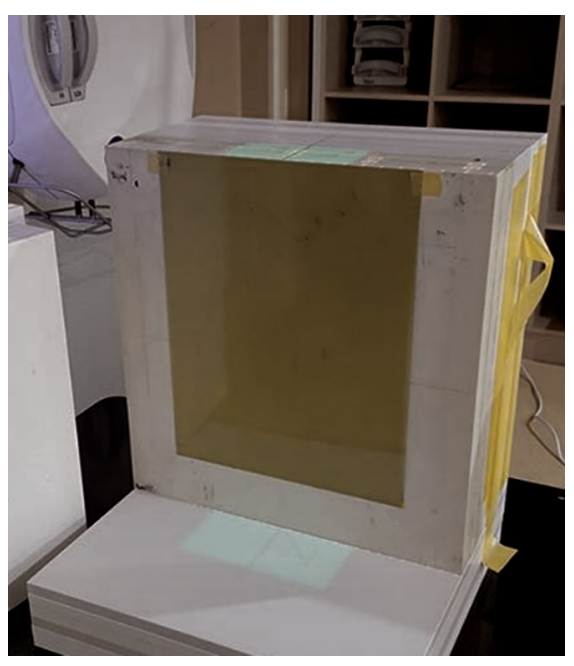

Figure 1 The location of the film.

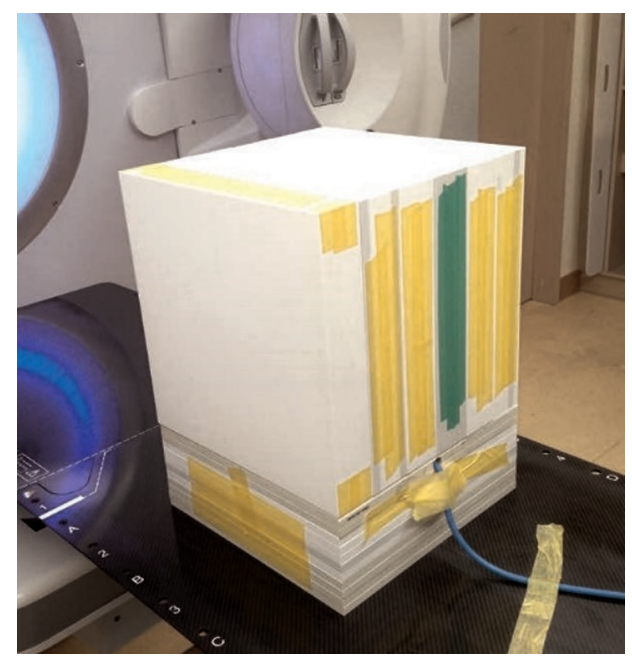

Figure 2 The whole experimental design.

phantom system to obtain a dose profile instead of a point dose. We have to rely on other measurement tools such as radiochromic films (9-12) to display dimensional dose distribution information.

The market is currently dominated by EBT3 films (11-13). The spatial resolution can be affected by film quality, film scanning conditions and the size of the film's analysis area. A film with a smaller analysis area has a larger spatial resolution. Nonetheless, the spatial resolution cannot be elevated indefinitely since the dose uncertainty will increase during the same process.

This study's purpose is to find a precise, accurate, and high spatially resolved dose profile by comparing three different dose measurement tools, semiflex chamber, EDGE detector, and EBT3 film. This study also identified the appropriate analysis area unit by determining the different analysis areas units of EBT3 films along with its dosimetric uncertainty.

\section{Methods}

The linear accelerator Elekta Versa $\mathrm{HD}^{\mathrm{TM}}$ used in this study produces $6 \mathrm{MV}$ photon beam with no wedge.

According to the American Association of Physicists in Medicine (AAPM)'s Task Group (TG) reports (Klein et al. 2009, Kutcher et al. 1994, Schulz et al. 1983), the field size of the linear accelerator is $20 \times 20 \mathrm{~cm}^{2}$ and the percentage depth dose (PDD) of water phantoms was measured. The obtained data was converted into the PDD of polystyrene since the density difference between the polystyrene and the water had an inverse square relationship with the distance between them. The analyzed data was further used as the PDD table of RW3.

\section{Film scanning}

Ten copies of EBT3 films (lot no. 12281503) were obtained from Epson Expression 11000XL scanning. The unexposed pixel value (PV) film was defined pre-scan. The scanning mode had 48-bit full color, $127 \mathrm{dpi}$ (5 pixels per $\mathrm{mm}$ ) with a high-quality spatial resolution (14). Scanning always used portrait orientation.

\section{The first batch of experimental exposure}

According to the experimental design of a previous reference (15), RW3 was stacked into a $30 \times 30 \times 30 \mathrm{~cm}^{3}$ cube. EBT3 film was placed vertically in the middle with the film facing toward the crosshairs in the in-plan direction (Figure 1). RW3 of the Farmer chamber was placed $1 \mathrm{~cm}$ below. Another $10 \mathrm{~cm} \mathrm{RW3}$ was stacked underneath it (Figure 2).

The field size was set to $20 \times 20 \mathrm{~cm}^{2}$ with the source to surface distance (SSD) as $100 \mathrm{~cm}$. Under flattening filter (FF) mode, the films were exposed under doses of $290 \mathrm{MU}$ and $88 \mathrm{MU}$, respectively, 5 times. The temperature and pressure were recorded using a Farmer chamber, where the dose at $31 \mathrm{~cm}$ of RW3.

The exposed films were treated for 72 hours and subsequently measured by scanning. The scanning resolution conditions were the same as those above to obtain the PV at 


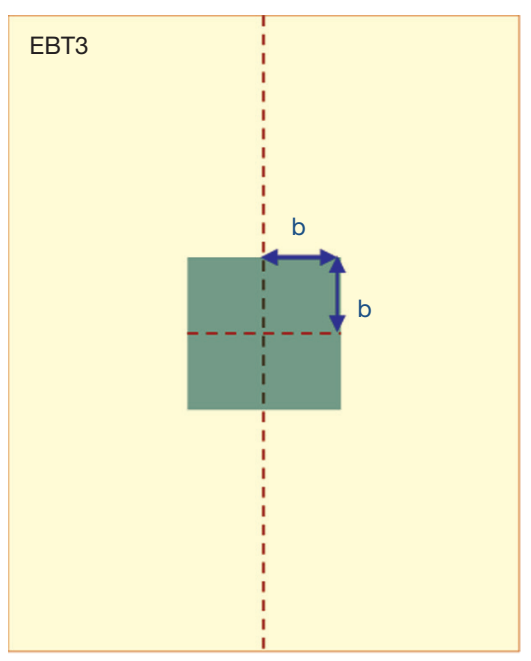

Figure 3 The selection method to analyze an area unit.

each point and this was defined as post-scan.

\section{Establishment of a dose fitting formula}

The analysis software Matlab (version 2016) was utilized. The image information of each film pre-scan and post-scan was transmitted into Matlab to obtain the PV under the red channel and then substituted into Eq. [1] to obtain the net optical density (NOD).

$$
N O D(i, j)=\log _{10}\left[\frac{P V_{\text {pre }}(i, j)}{P V_{p o s t}(i, j)}\right]
$$

where $(i, j)$ refers to the position of the point on the film, $P V_{\text {pre }}$ indicates the pre-scan $\mathrm{PV}$, and $P V_{\text {post }}(i, j)$ indicates the post-scan PV.

Along the central axis of the long side of the film, the unit of analysis area (Figure 3) was selected as $0.8 \times 0.8 \mathrm{~cm}^{2}$ $(b=0.4)$. All NOD values within this area were calculated and averaged. The selection range was $1.8-23.4 \mathrm{~cm}$ in terms of the depth of the film. Samples were collected at a $0.2 \mathrm{~cm}$ interval and each film could usually obtain 108 NOD values.

The NOD values obtained at the same depth for the five films of $290 \mathrm{MU}$ and $88 \mathrm{MU}$ are averaged again. The dose measured by the Farmer chamber on the day of the experiment was processed by the temperature and pressure correction formula and subsequently matched with the RW3 PDD table to determine the absolute dose corresponding to each depth NOD value on the film. The processed data was introduced into Eq. [2] in Matlab.

$$
D_{\text {fit }}=a \times N O D+b \times N O D^{c}
$$

$D_{f i t}$ is the dose obtained after fitting-defined as the fitted dose-and a, b, c are the fitting parameters.

No range was set for the first fitting parameters a and b. Parameter $\mathrm{c}$ was limited to $1-3$. After obtaining the appropriate parameter $\mathrm{c}$, the second fitting was performed. Parameter $\mathrm{c}$ was then fixed to reduce the uncertainty.

A complete equation was established after the calculation of all three parameters. Eq. [3] summarized the methods of calculating the uncertainty rates according to the guidelines of the Joint Committee for Guides in Metrology.

$$
u_{c}^{2}(y)=\sum_{i=1}^{N}\left(\frac{\partial f}{\partial x_{i}}\right)^{2} u^{2}\left(x_{i}\right)
$$

$u_{c}(\mathrm{y})$ is the overall uncertainty and $x_{i}$ is the value that impacted the uncertainty. There are a total of i, $u\left(x_{i}\right)$ is the standard deviation of the factors that impacted the uncertainty, and $\left(\frac{\partial f}{\partial x_{i}}\right)$ is the value after differentiating $u\left(x_{i}\right)$.

Two uncertainty sources may exist for this experiment, the scanning NOD values and the uncertainty caused by the fitting parameter in the fitting equation. Two uncertainty rates can be introduced into Eq. [4] to calculate the inaccurate percentage of doses, represented by $\delta_{d o s e \%}$.

$$
\begin{aligned}
& \delta_{\text {dose } \%}=\frac{\sqrt{\delta_{\text {exp }}^{2}+\delta_{f i t}^{2}}}{D_{f i t}} \times 100 \% \\
& \delta_{\text {exp }}=\sqrt{\left(a+c \cdot b \cdot N O D^{c-1}\right)^{2} \cdot \delta_{N O D}^{2}} \\
& \delta_{f i t}=\sqrt{N O D^{2} \cdot \delta_{a}^{2}+N O D^{2 c} \cdot \delta_{b}^{2}} \\
& \delta_{\text {NOD }}=\frac{\sqrt{\left(\frac{\delta_{P V_{\text {pre }}}}{P V_{\text {pre }}}\right)^{2}+\left(\frac{\delta_{P V_{\text {post }}}}{P V_{p o s t}}\right)^{2}}}{\ln 10}
\end{aligned}
$$

$\delta_{\text {dose } \%}$ is the percentage of the uncertainty of the dose obtained using the dose fitting equation; $\delta_{\exp }$ is the uncertainty of the obtained NOD value, which also represents the standard deviation caused by the experiment; $\delta_{f i t}$ refers to the uncertainty caused by parameters a and b in the dose fitting formula, which equals to the standard deviation of the dose fitting equation; $\delta_{N O D}$ is the uncertainty caused by PV. This was obtained by processing the $P V_{\text {pre }}$ of the pre-scan and the $P V_{\text {post }}$ of the post-scan to calculate the obtained standard deviation. 


\section{The second batch of experimental exposure}

Four copies of EBT3 films (lot no. 04201503) were used. RW3 was stacked into a $30 \times 30 \times 30 \mathrm{~cm}^{3}$ cube and another $10 \mathrm{~cm}$-thick RW3 was directly stacked underneath the first cube. The film was placed in the center of the upright RW3.

The SSD was $100 \mathrm{~cm}$. Under the FFF mode, the field size was set to $2 \times 2$ and $3 \times 3 \mathrm{~cm}^{2}$. Each field of view was exposed to $200 \mathrm{MU}$ twice and the irradiated films were in place for 72 hours and used in scanning afterward.

The image information of each film pre-scan and postscan was transmitted into Matlab to obtain the PV under the red channel and then substituted into Eq. [1] to obtain the NOD. The NOD values for a $2 \times 2$ and $3 \times 3 \mathrm{~cm}^{2}$ field size were subsequently averaged.

In the second batch of experimental analysis, the area unit is defined as below: $b=0.04, b=0.08, b=0.2$, and $b=0.4$. The NOD values in the area were averaged and substituted into the dose fitting Eq. [2] obtained in the first batch of experiments to calculate the value of the dot dose.

The dose profiles of the different depths 5,10 , and $20 \mathrm{~cm}$ were analyzed and compared with the same set of data in the EDGE detector and the semiflex chamber. Subsequently, the percentage differences between the various dose profiles were analyzed.

The differences between the dose points of EDGE detector and semiflex chamber were calculated by Eq. [8] below.

$$
\frac{D P_{-} \text {semiflex chamber }-D P_{-} E D G E \text { detector }}{D P \_E D G E \text { detector }} \times 100 \%[8]
$$

$D P \_s e m i f l e x$ chamber represents the dose profile measured by the semiflex chamber, while DP_EDGE detector represents the dose profile measured by the EDGE detector.

The differences between the dose points of EBT3 films and EDGE detector were calculated using Eq. [9] below. The same method is applied to EBT3 and semiflex chamber (Eq. [10]).

$$
\begin{aligned}
& \frac{D P_{-} E B T 3-D P_{\_} E D G E \text { detector }}{D P_{-} E B T 3} \times 100 \% \\
& \frac{D P_{-} E B T 3-D P_{-} \text {semiflex chamber }}{D P_{-} E B T 3} \times 100 \%
\end{aligned}
$$

$D P \_E B T 3$ represents the dose profile measured using EBT3 films, DP_semiflex chamber represents the dose profile measured using the semiflex chamber, and $D P \_E D G E$ detector represents the dose profile measured using the EDGE detector.

\section{Results}

\section{Comparison of the measured dose profiles using EDGE detector and semiflex chamber}

Figures 4,5 show comparisons of the dose profiles measured using the EDGE detector and semiflex chamber in FFF mode. The $\mathrm{X}$-axis represents the distance from the central axis of the beam. The symmetry of the beam was evaluated and shown in the figure. When the distance is positive, it represents dose profile location closer to gantry and vice versa. The $\mathrm{Y}$-axis represents the percentage differences in the dose profiles. The doses were measured within $1.6 \mathrm{~cm}$ for a $2 \times 2 \mathrm{~cm}^{2}$ field size while they were analyzed within $2.4 \mathrm{~cm}$ for a $3 \times 3 \mathrm{~cm}^{2}$ field size. Profile measurements were made with depth of 5,10 , and $20 \mathrm{~cm}$.

\section{The analysis of $\delta_{\text {dose\% }}$ with different $b$ values}

Figure 6 shows the $\delta_{\text {dose }}$ - the percentage of dosimetric accuracy-for different radiation doses and calculated with $b$ values of $0.04,0.08,0.2$, and 0.4 . The $\delta_{\text {dose } \%}$ calculated with b values of 0.04 or 0.08 were larger than those with $\mathrm{b}$ values defined as 0.2 or 0.4 . With a low radiation dose of 30-60 cGy, the differences between $\delta_{\text {dose }} \%$ might reach $2 \%$ at most.

\section{The comparison of measured dose profiles between EBT3 films and the semiflex chamber and also between EBT3 and the EDGE detector}

Figures 7,8 show comparisons of measured dose profiles between EBT3 films and semiflex chamber and between EBT3 films and EDGE detector for depths of 5, 10 , and $20 \mathrm{~cm}$ under FFF mode. The doses were measured within $1.6 \mathrm{~cm}$ for a $2 \times 2 \mathrm{~cm}^{2}$ field size and were analyzed within $2.4 \mathrm{~cm}$ for a $3 \times 3 \mathrm{~cm}^{2}$ field size. The b value, which defines the analysis unit, was 0.08 for the analysis of both field sizes.

\section{The comparison of dose profiles with different $b$ values}

Figures 9,10 show the comparison of the dose profiles measured by EBT3 films to those measured by either 


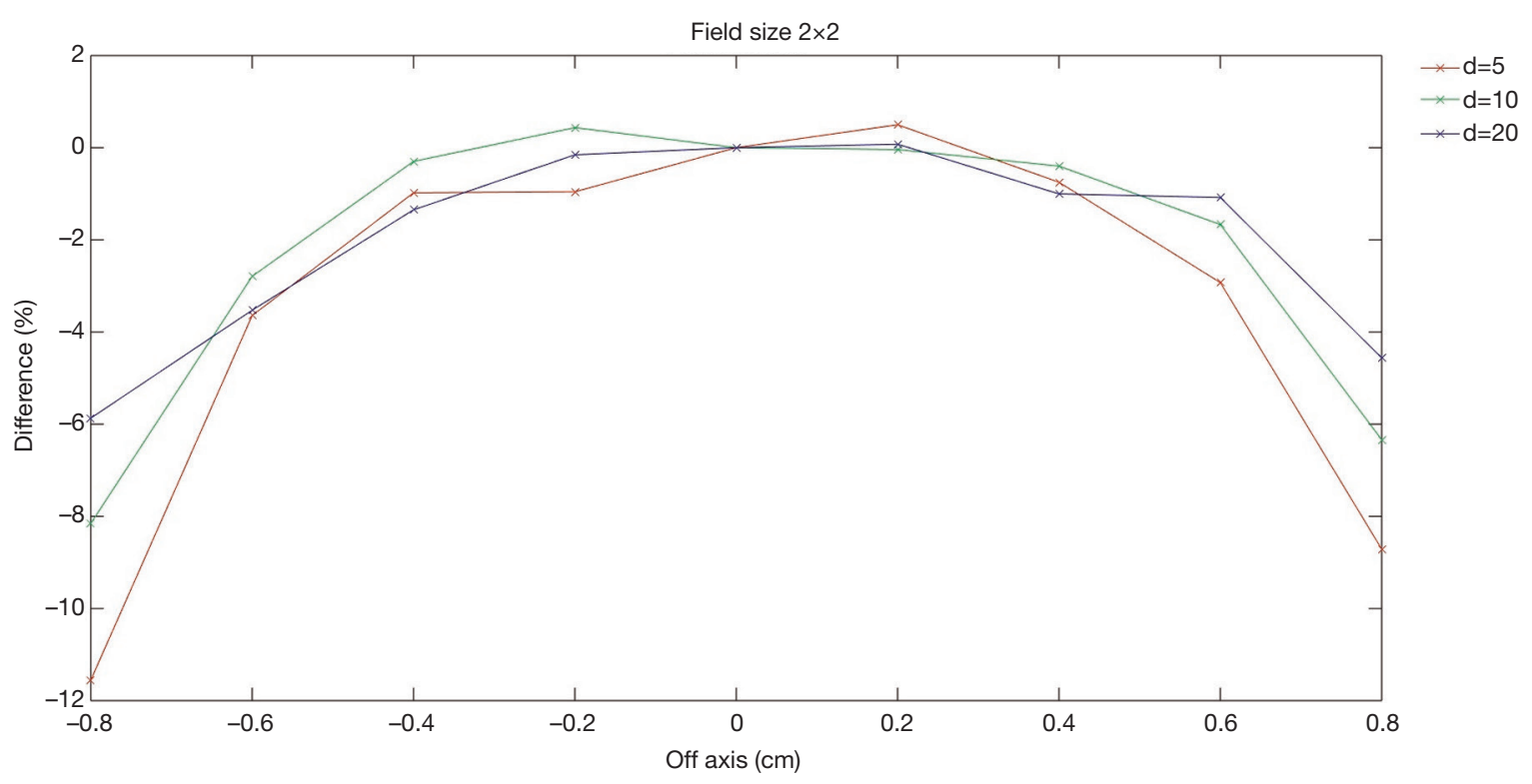

Figure 4 The comparison of dose profiles measured by the EDGE detector and semiflex chamber in a $2 \times 2 \mathrm{~cm}^{2}$ field size.

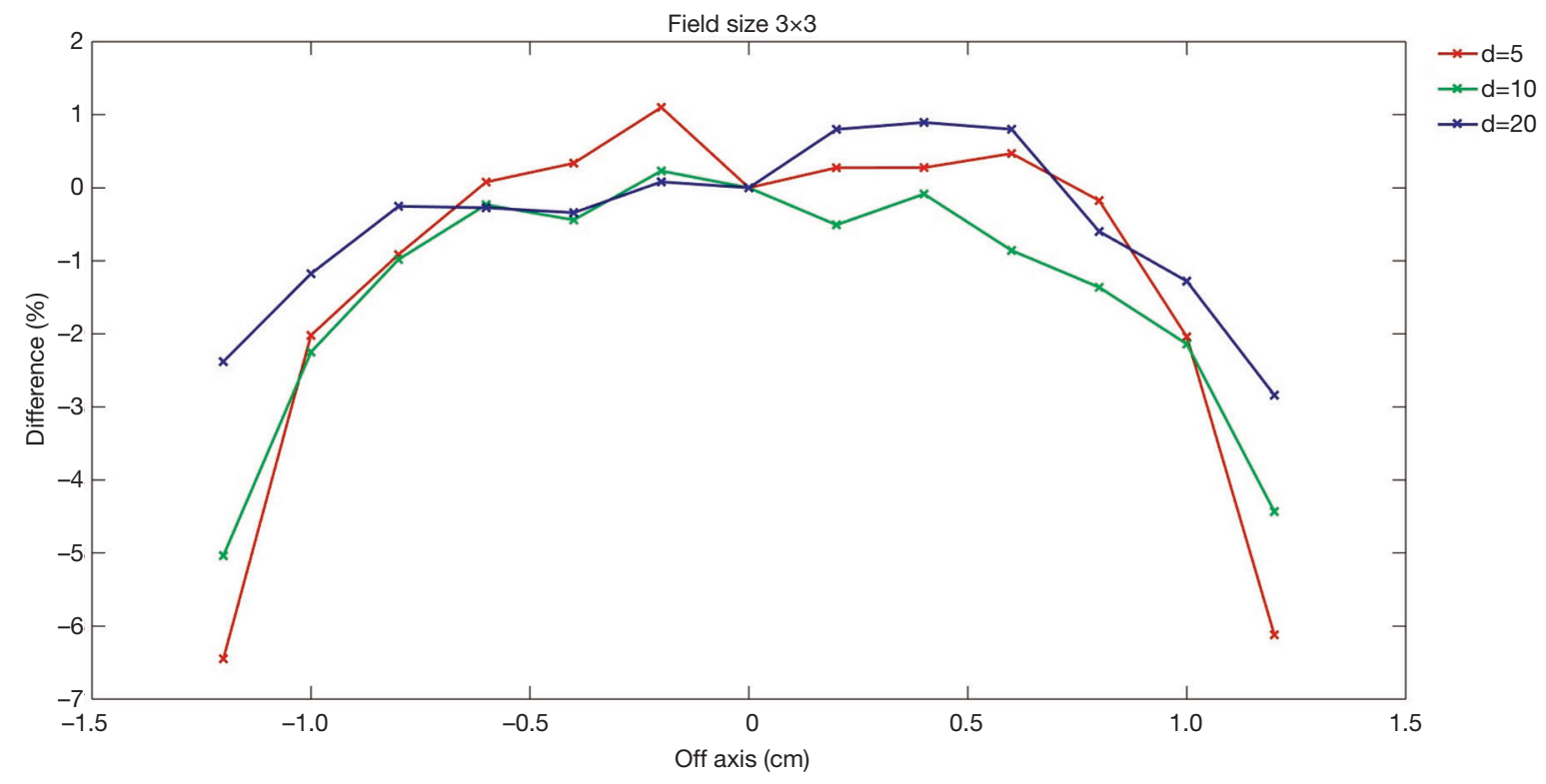

Figure 5 The comparison of dose profiles measured by the EDGE detector and semiflex chamber in a $3 \times 3 \mathrm{~cm}^{2}$ field size.

EDGE detector or semiflex chamber with four different $b$ values either in a $2 \times 2 \mathrm{~cm}^{2}$ or a $3 \times 3 \mathrm{~cm}^{2}$ field. The b values for Figure $9 A$ and Figure 10A, Figure $9 B$ and Figure 10B, Figure $9 C$ and Figure 10C, Figure 9D and Figure $10 D$ were $0.04,0.08,0.2$, and 0.4 , respectively. The furthest points from the central beam axis in the $2 \times 2$ and $3 \times 3 \mathrm{~cm}^{2}$ fields were \pm 0.8 and $\pm 1.2 \mathrm{~cm}$, respectively.

\section{Discussion}

The EDGE detector has an active volume of $0.019 \mathrm{~mm}^{3}$. In contrast, the semiflex chamber has an active volume of $0.125 \mathrm{~cm}^{3}$, which is over 6,000-fold that of the EDGE detector. Usually, the smaller the active volume, the higher the spatial resolution. Additionally, the severe average 


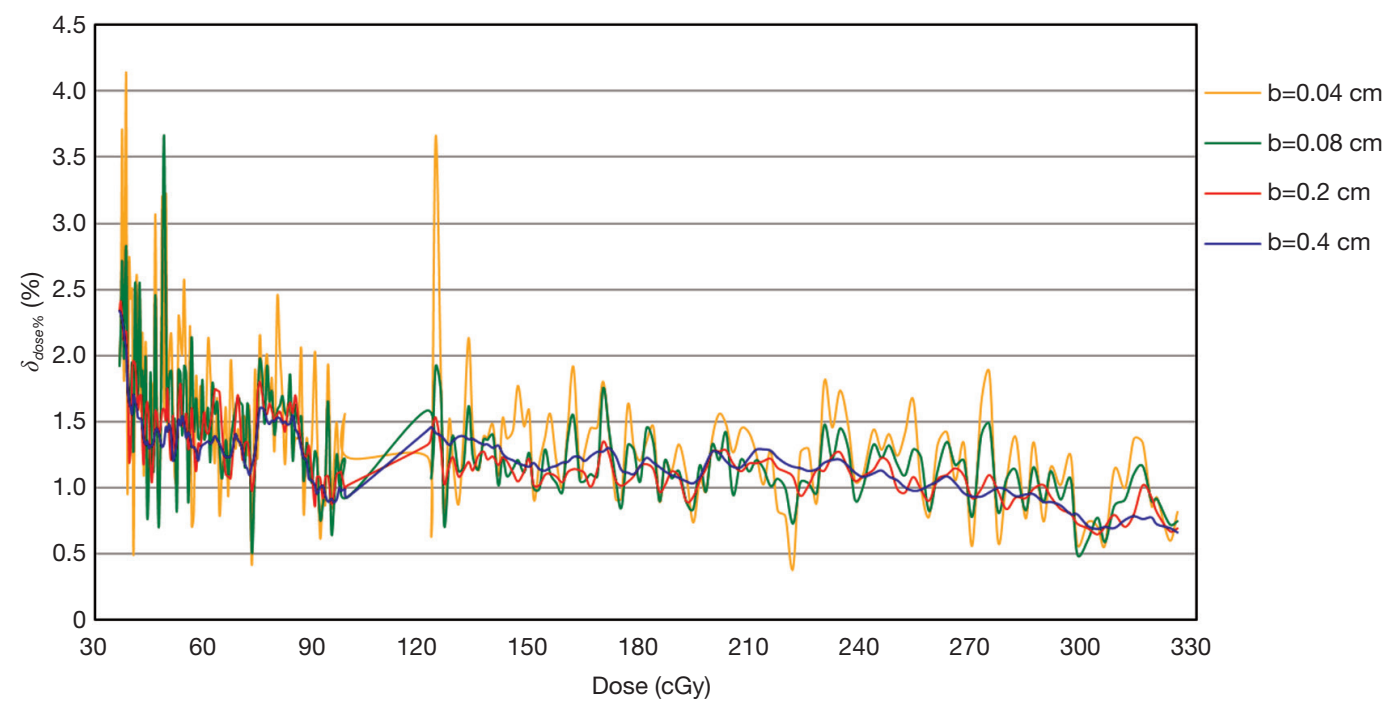

Figure 6 Analysis of $\delta_{d o s e}$ with different b values.

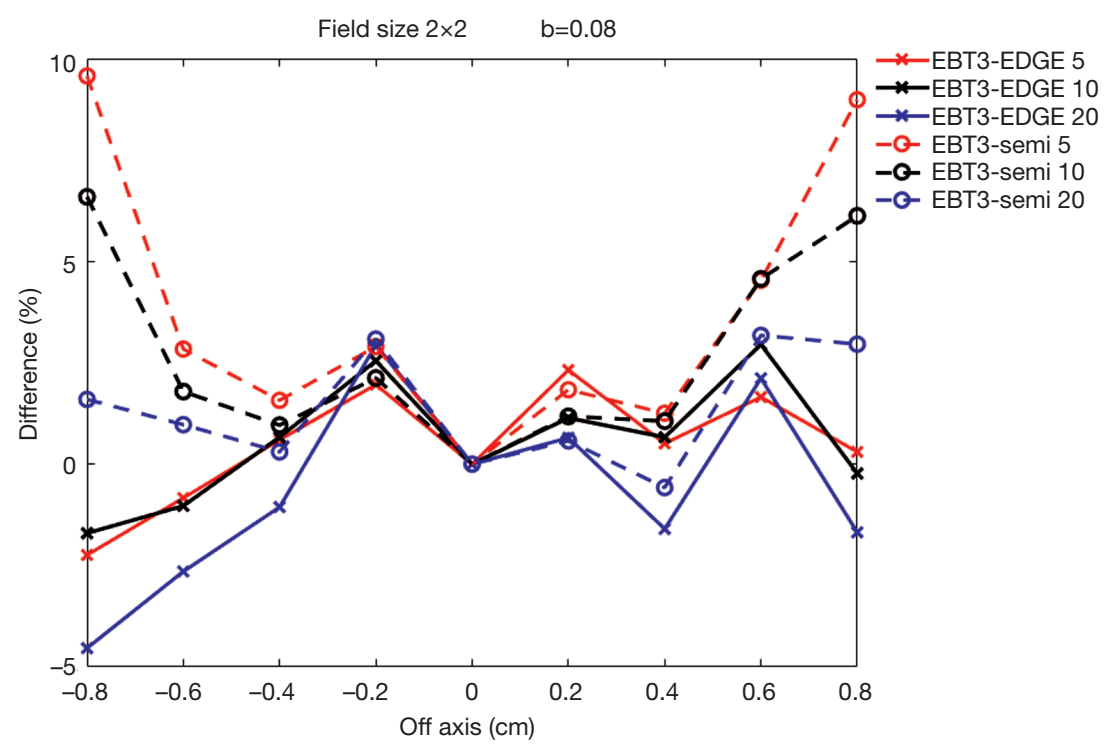

Figure 7 A comparison of dose profiles measured by EBT3 films to those measured by either EDGE detector or semiflex chamber in the $2 \times 2 \mathrm{~cm}^{2}$ field size.

volume effect of the semiflex chamber leads to an even lower spatial resolution, particularly in the large gradient region of the dose distribution. Consistently, Figures 4,5 have shown that larger differences were detected in the dose profile measurements at the depth of $5 \mathrm{~cm}$ compared to that measured at the depths of 10 and $20 \mathrm{~cm}$.

It is critical to determine the b value unit used in this study to optimize between EBT3 film spatial resolution and measurement accuracy. As the field (b value) becomes smaller, the higher the contribution of noise. Therefore, measurements by EBT3 film may not achieve as high a spatial resolution as an EDGE detector. The spatial resolution, or changes in the gradient of the dose profile throughout the field, is of interest in this study. Therefore, the uncertainty $\left(\delta_{d o s e} \%\right)$, of varying b value is shown in Figure 6. B values of 0.2 and 0.4 were excluded, even though the $\delta_{\text {dose }} \%$ was low, the spatial resolution was sacrificed. Within the radiation dose of 100-300 cGy, it was observed that $b=0.08$ showed a more 


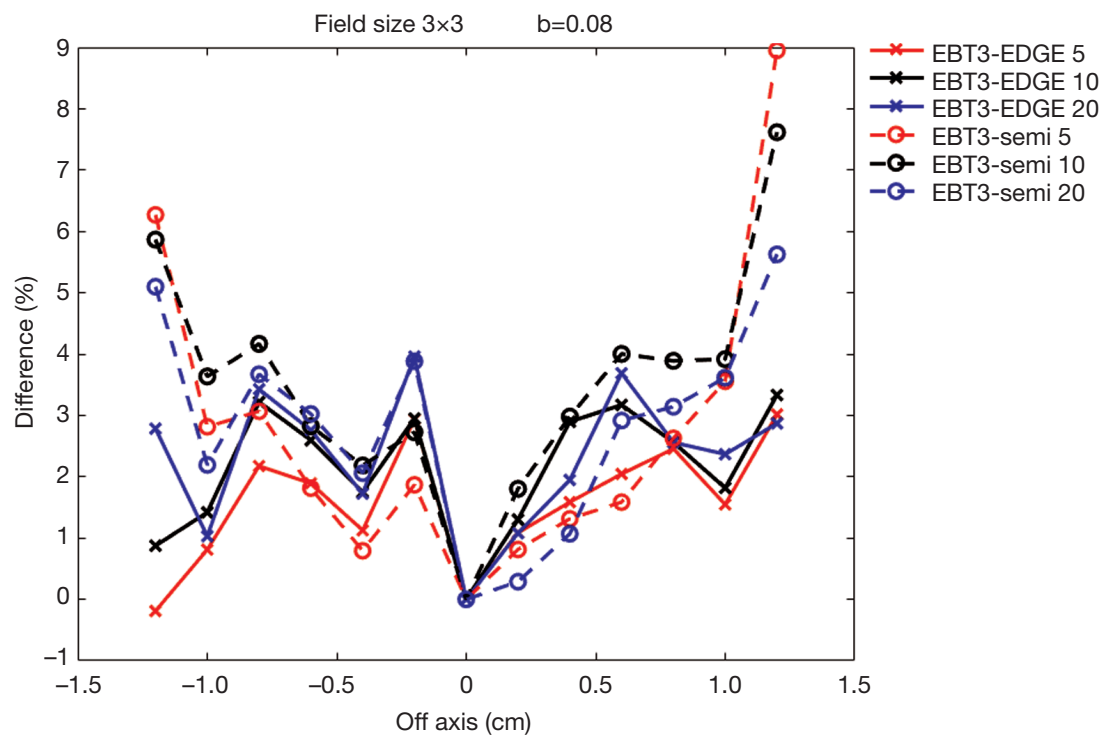

Figure 8 A comparison of dose profiles measured by EBT3 to those measured by either the EDGE detector or semiflex chamber in the $3 \times 3 \mathrm{~cm}^{2}$ field size.
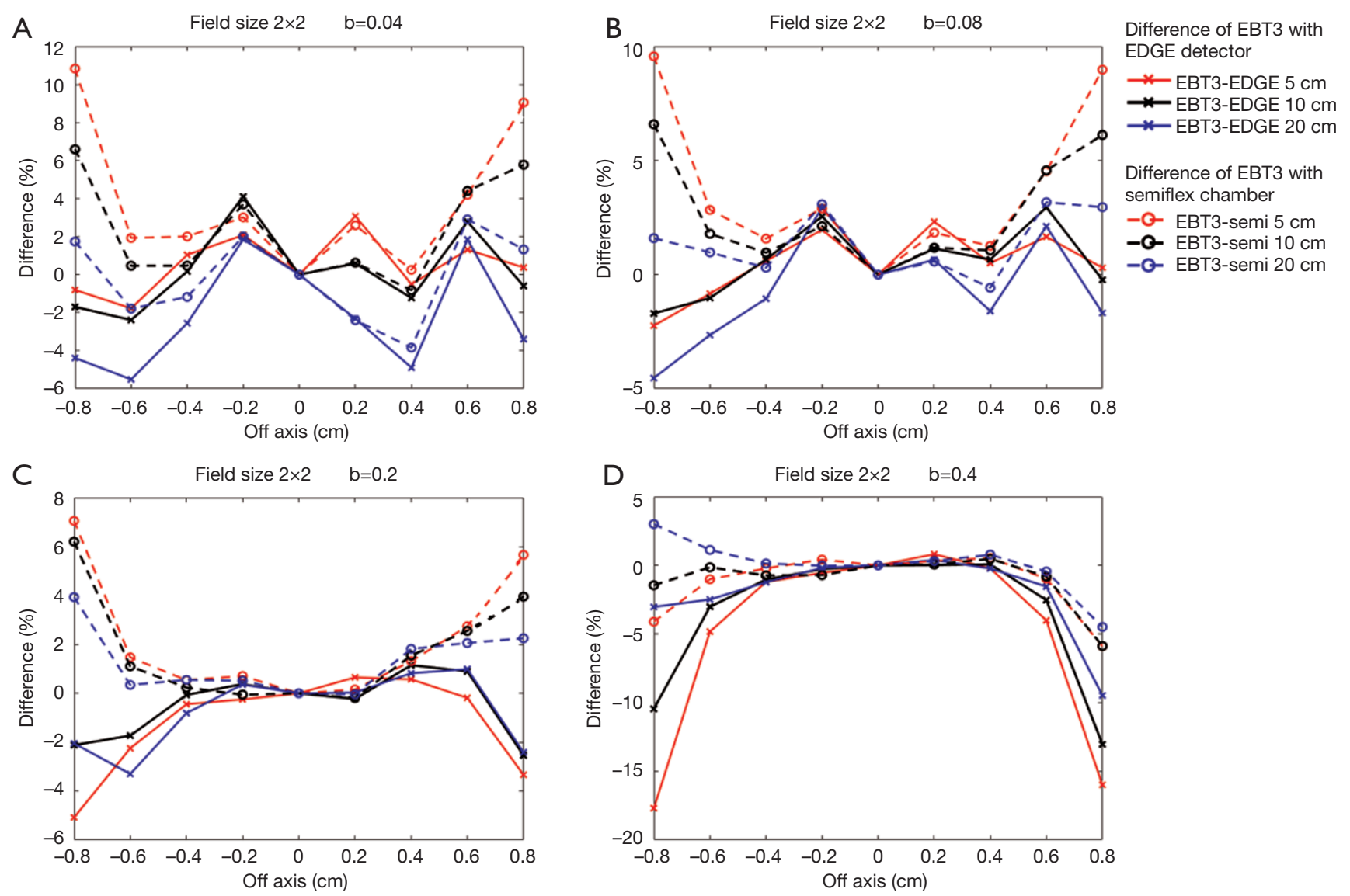

Figure 9 Graphical representation of varying depth dose profile comparison of EBT3 film versus either EDGE detector (x) or semiflex chamber (o) with varying b values (the unit of analysis area): (A) b=0.04 cm, (B) b=0.08 cm, (C) b=0.2 cm, and (D) b=0.4 cm. Field size is $2 \times 2 \mathrm{~cm}^{2}$. 

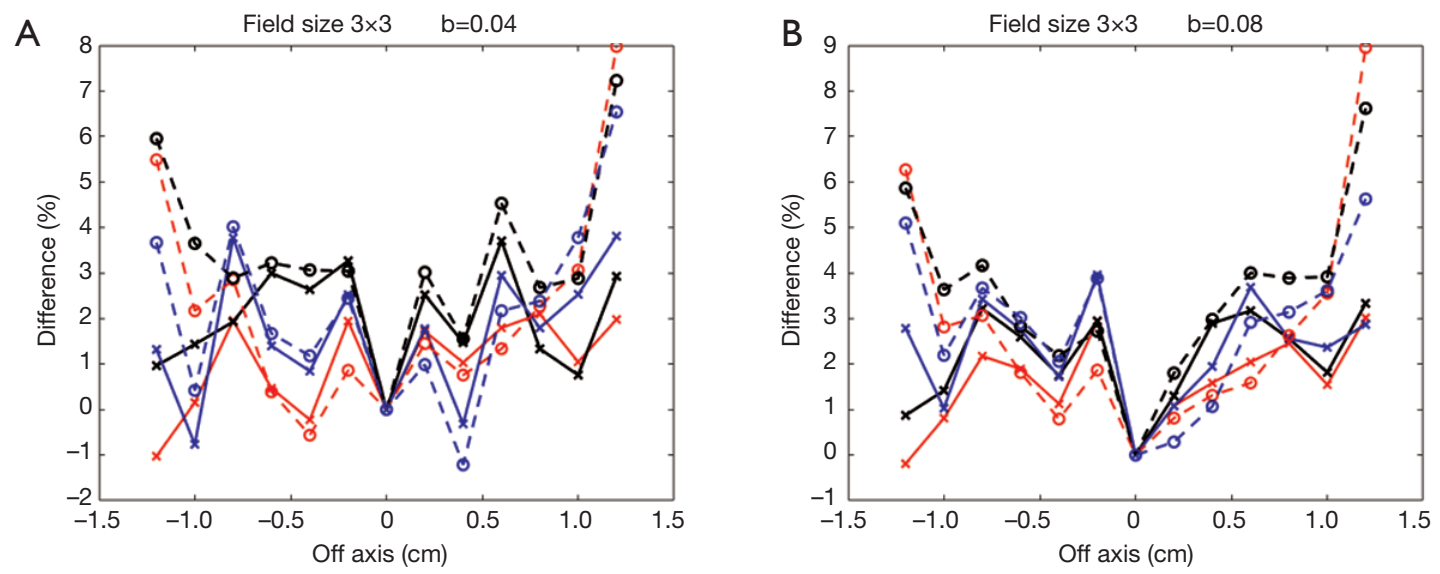

Difference of EBT3 with EDGE detector

$\because$ EBT3-EDGE $5 \mathrm{~cm}$ * EBT3-EDGE $10 \mathrm{~cm}$ * EBT3-EDGE $20 \mathrm{~cm}$

Difference of EBT3 with semiflex chamber -G- EBT3-semi $5 \mathrm{~cm}$ -Q- EBT3-semi $10 \mathrm{~cm}$ - - EBT3-semi $20 \mathrm{~cm}$
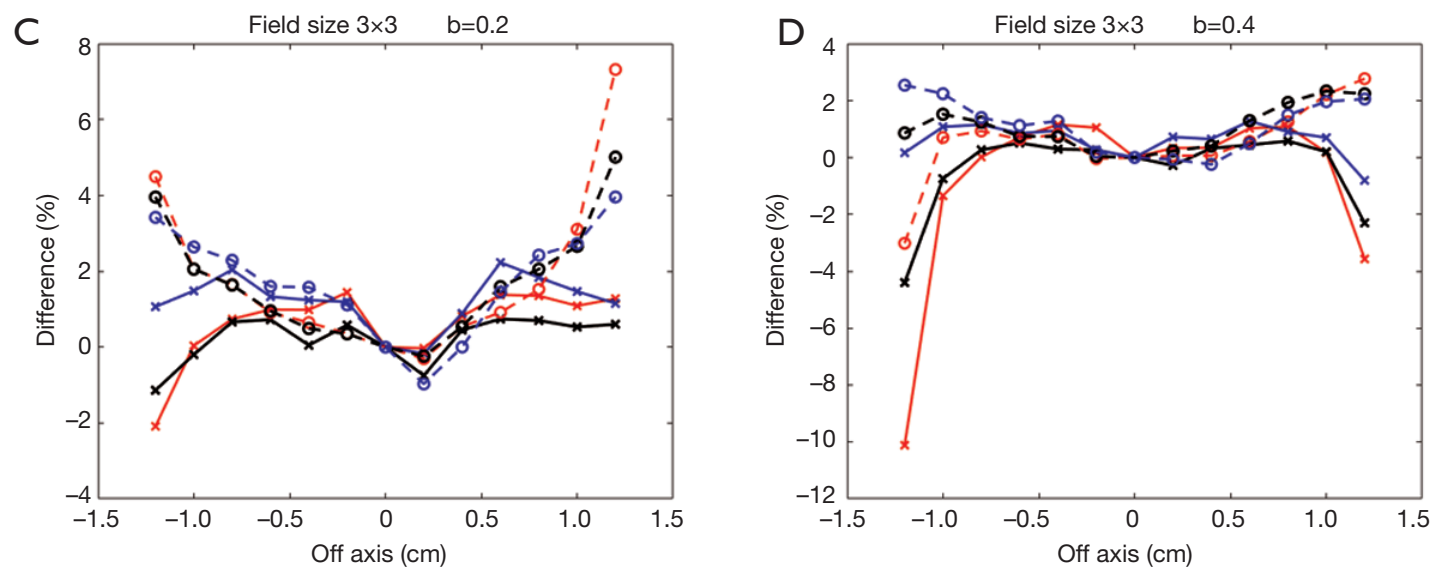

Figure 10 Graphical representation of varying depth dose profile comparison of EBT3 film versus either EDGE detector (x) or semiflex chamber (o) with varying b values (the unit of analysis area): (A) $b=0.04 \mathrm{~cm},(\mathrm{~B}) \mathrm{b}=0.08 \mathrm{~cm},(\mathrm{C}) \mathrm{b}=0.2 \mathrm{~cm}$, and (D) b=0.4 cm. Field size is $3 \times 3 \mathrm{~cm}$.

consistent $\delta_{\text {dose } \%}$, signifying a greater balance between signal and noise. $B$ value $=0.04$ showed excessive noise when the radiation dose was $122.6 \mathrm{cGy}$.

When the $b$ value was fixed at 0.08 , the field of analysis radiation area for EBT3 films, the EDGE detector, and the semiflex chamber were $0.0256,0.0064$, and $0.3575 \mathrm{~cm}^{2}$, respectively. Among the three different measurement methods, EDGE detector achieved the highest spatial resolution.

EBT3 films shows greater flexibility in by adjusting the field size for analysis and can complement a variety of dose measurement tools. Its measurement was similar to the EDGE detector measurement when its analysis area was close to the field of analysis of the EDGE detector. Similarly, its measurement was similar to the semiflex chamber measurement when its analysis area was close to the field of analysis of the semiflex chamber. Consistently, Figures 9,10 have shown that the differences in the dose profile measurements between EBT3 films and EDGE detector became larger as the $\mathrm{b}$ value increased, while the differences in the dose profile measurements between EBT3 films and the semiflex chamber reduced. This observation is because as b value increases, the spatial analysis area approaches the analysis area of semiflex chamber.

Figures 7,8 show that the does profile measurements with EBT3 films and EDGE detector were similar for the depths 5,10 , and $20 \mathrm{~cm}$ under the same radiation dose. This showed that EBT3 film has the ability to be correlative to EDGE detector; especially at areas where the dose profile gradient is large when compared to measurements obtained from semiflex chamber. The only exception was with the measurements on the point that was $-0.8 \mathrm{~cm}$ from the central beam axis in the $2 \times 2 \mathrm{~cm}^{2}$ field size with the $20 \mathrm{~cm}$ depth. The difference in the measured dose profile with EBT3 films and EDGE detector was $4.54 \%$, while the difference in the measured dose profile with EBT3 films and the semiflex 
chamber was $1.6 \%$, which was smaller than that measured with EBT3 films and EDGE detector. This was due to inaccuracies resulting from the dose fitting equation, as the uncertainty was increased with smaller radiation doses.

\section{Conclusions}

The EDGE detector had the highest spatial resolution. Our results show that the dose profile measured at the same point with the same field sizes and at the same depth ranked from high to low were: EDGE detector, EBT3 films, and semiflex chamber. As the more accurate dose profiles measured in FFF mode led to more accurate treatment planning, using the EDGE detector was recommended instead of the currently widely used semiflex chamber to measure the dose profiles and serve as the gold standard.

By adjusting the field size, EBT3 film can offer great flexibility to complement EDGE detector, semiflex chamber or other does measurement tools.

Dose profile measured with EBT3 films showed that as one reduces the analysis area, the dose profile is more refined but also comes with greater dosimetric uncertainty, especially at lower radiation dose. Therefore, lowering the $b$ values might not always lead to definite dose profile measurements. Our results have indicated that the optimal setting for the $\mathrm{b}$ value was 0.08 as it provides the desired balance between spatial resolution and uncertainty.

\section{Acknowledgments}

Funding: The work was supported by the Research Support Scheme of the E-DA hospital, grant no. EDAHT106022 and EDAHP106034.

\section{Footnote}

Conflicts of Interest: All authors have completed the ICMJE uniform disclosure form (available at http://dx.doi. org/10.21037/tro.2019.09.02). The authors have no conflicts of interest to declare.

Ethical Statement: The authors are accountable for all aspects of the work in ensuring that questions related to the accuracy or integrity of any part of the work are appropriately investigated and resolved.

Open Access Statement: This is an Open Access article distributed in accordance with the Creative Commons Attribution-NonCommercial-NoDerivs 4.0 International License (CC BY-NC-ND 4.0), which permits the noncommercial replication and distribution of the article with the strict proviso that no changes or edits are made and the original work is properly cited (including links to both the formal publication through the relevant DOI and the license). See: https://creativecommons.org/licenses/by-nc-nd/4.0/.

\section{References}

1. Meshram MN, Pramanik S, Ranjith CP, et al. Dosimetric properties of equivalent-quality flattening filter-free (FFF) and flattened photon beams of Versa HD linear accelerator. J Appl Clin Med Phys 2016;17:358-70.

2. Fogliata A, Fleckenstein J, Schneider F, et al. Flattening filter free beams from TrueBeam and Versa HD units: Evaluation of the parameters for quality assurance. Med Phys 2016;43:205.

3. Kumar A, Mukherjee G, Yadav G, et al. Optimized point dose measurement: an effective tool for QA in intensitymodulated radiotherapy. J Med Phys 2007;32:156-60.

4. Syam Kumar SA, Sukumar P, Sriram P, et al. A patientspecific quality assurance study on absolute dose verification using ionization chambers of different volumes in RapidArc treatments. Med Dosim 2012;37:436-41.

5. Kontra G, Major T, Polgár C. Measurement of peak correction factor of Farmer chamber for calibration of flattening filter free (FFF) clinical photon beams. Magy Onkol 2015;59:119-23.

6. Fox C, Simon T, Simon B, et al. Assessment of the setup dependence of detector response functions for megavoltage linear accelerators. Med Phys 2010;37:477-84.

7. Cheng JY, Ning H, Arora BC, et al. Output factor comparison of Monte Carlo and measurement for Varian TrueBeam $6 \mathrm{MV}$ and $10 \mathrm{MV}$ flattening filter-free stereotactic radiosurgery system. J Appl Clin Med Phys 2016;17:100-10.

8. McAuley GA, Teran AV, Slater JD, et al. Evaluation of the dosimetric properties of a diode detector for small field proton radiosurgery. J Appl Clin Med Phys 2015;16:51-64.

9. Devic S, Tomic N, Lewis D. Reference radiochromic film dosimetry: Review of technical aspects. Phys Med 2016;32:541-56.

10. Gonzalez-Lopez A, Vera-Sanchez JA, Lago-Martin JD. Small fields measurements with radiochromic films. J Med Phys 2015;40:61-7.

11. Liu HW, Gräfe J, Khan R, et al. Role of in vivo dosimetry 
with radiochromic films for dose verification during cutaneous radiation therapy. Radiat Oncol 2015;10:12.

12. Palmer AL, Bradley D, Nisbet A. Evaluation and implementation of triple-channel radiochromic film dosimetry in brachytherapy. J Appl Clin Med Phys 2014;15:4854.

13. Marroquin EY, Herrera González JA, Camacho López MA, et al. Evaluation of the uncertainty in an EBT3 film dosimetry system utilizing net optical density. J Appl Clin Med Phys 2016;17:466-81.

14. Ferreira BC, Lopes MC, Capela M. Evaluation of an Epson flatbed scanner to read Gafchromic EBT films for radiation dosimetry. Phys Med Biol 2009;54:1073-85.

15. Chang L, Chui CS, Ding HJ, et al. Calibration of EBT2 film by the PDD method with scanner non-uniformity correction. Phys Med Biol 2012;57:5875-87. doi: $10.21037 /$ tro.2019.09.02

Cite this article as: Hsueh HP, Yeh SA, Chang L. The comparison of spatial resolution of ion chamber, diode, and EBT3 film based on the dose profile. Ther Radiol Oncol 2019;3:35. 